\title{
Jatkuvasatoisen mansikan kasvinsuojelu tunneliviljelyssä
}

\author{
Tuomo Tuovinen ${ }^{1)}$, Isa Lindqvist ${ }^{1)}$ ja Saila Karhu ${ }^{2)}$ \\ 1) MTT Kasvintuotannon tutkimus, 31600 Jokioinen, tuomo.tuovinen@mtt.fi, isa.lindqvist@mtt.fi \\ ${ }^{2)}$ MTT Kasvintuotannon tutkimus, 21500 Piikkiö, saila.karhu@mtt.fi
}

\section{Tiivistelmä}

Hankkeessamme (2007-2010) tutkitaan jatkuvasatoisen mansikan lajikkeita ja viljelytekniikkaa. Kasvinsuojeluosion tavoitteena on selvittää mansikan kasvintuhoojien merkitystä ja esiintymistä avomaa- ja tunneliviljelyssä kolmella jatkuvasatoisella lajikkeella sekä tutkia ja soveltaa biologisen torjunnan menetelmiä tärkeimpien kasvintuhoojien torjuntaan. Tutkimukseen ja kirjallisuuteen perustuen laaditaan jatkuvasatoisen mansikan kasvinsuojeluohjeisto.

Avomaan ja tunneliviljelyn koealueille Jokioisilla istutettiin keväällä 2008 lajikkeet Malling Opal, Rita ja Rondo. Alueilla seurattiin tuholaisten ja hyödyllisten hyönteisten ja punkkien esiintymistä näytteiden avulla. Tautien torjuntaruiskutuksia ei tehty ja tuholaisten torjuntaan käytettiin petopunkkeja ja petoluteita. Sato lajiteltiin marjakoon, tuholais- ja tautivioitusten ja muiden vioitusten mukaan ja punnittiin. Tuloksia esitetään lähinnä vuoden 2008 havaintojen pohjalta.

Vihannespunkki ja ripsiäiset olivat yleisimmät tuholaislajit. Ansaripetopunkki oli tehokkain vihannespunkin torjuntaeliö kausihuoneessa. Ripsiäisiä esiintyi eniten Rita-lajikkeella ja niitä torjuttiin ripsiäispetopunkkien ja kesärikkaluteiden avulla. Vattukärsäkästä ja sen vioituksia esiintyi melko vähän eikä torjuntaan ryhdytty. Myös peltoluteiden vioitukset olivat vähäisiä. Rapsikuoriaisia esiintyi kukissa runsaasti loppukesällä 2009, mutta ne eivät aiheuttaneet mainittavia vioituksia. Valkovyölehtiäisen toukat vioittivat lähinnä lehtiä, yökköstoukat, kääriäistoukat, maakiitäjäiset ja etanat vioittivat myös kypsyviä marjoja. Lehtikirvoja esiintyi ajoittain, mutta niiden määrä pysyi vähäisenä. Räkättirastas ja peltomyyrä olivat tärkeitä tuholaisia, jotka on torjuttava ennakolta. Harmaahomeen vioittamia marjoja oli avomaalla moninkertaisesti tunneliin verrattuna. Mansikan härmää ei esiintynyt marjoissa lainkaan. Muita kuin tautien tai tuholaisten aiheuttamia vioituksia esiintyi eniten avomaalla lähinnä säätekijöistä johtuen. Kauppakelpoinen sato oli tunneliviljelyssä 7172\% kokonaissadosta, avomaalla vain 43\% (Malling Opal), 41\% (Rita) ja 59\% (Rondo).

Jatkuvasatoisella mansikalla tunneliviljely on välttämätöntä etenkin harmaahomeen aiheuttaman riskin vähentämiseksi. Tutkimuksessamme mansikan härmästä ei ollut haittaa, mutta käytännössä härmän torjunta on olennainen osa tunneliviljelyä. Vihannespunkin torjunta onnistuu tunnelissa ansaripetopunkkien avulla hyvin. Petopunkkilevityksiä on tarvittaessa tehtävä useaan kertaan. Ripsiäisten ja kirvojen torjunta petopunkkien tai petoluteiden avulla onnistunee paremmin tunnelissa kuin avomaalla. Muiden tuholaisten torjuntaan on käytettävä kasvinsuojeluaineita.

\section{Asiasanat}

Mansikka, jatkuvasatoiset lajikkeet, kasvinsuojelu, biologinen torjunta, tuhoeläimet, kasvitaudit 


\section{Johdanto}

Suomessa viljeltyjen lyhyen päivän mansikkalajikkeiden kukka-aiheet kehittyvät satoa edeltävänä syksynä. Sato muodostuu keväällä kehittyvien kukkavanojen kukinnan mukaan ja lajikekohtainen sadon tuotto kestää vain joitakin viikkoja. Tästä aiheutuu monia ongelmia. Loppusadon marjat ovat lajikkeesta riippumatta pieniä kukkavanojen 3. ja 4. asteen marjoja verrattuna ensimmäisenä kypsyviin 1. ja 2. asteen marjoihin. Kukinta-aika on lyhyt ja etenkin kukinnan alkupuoliskon aikaan sattuvat runsaat sateet tai hallat haittaavat tuotantoa. Sadonkorjuu vaatii suuren määrän poimijoita samaan aikaan. Mansikkamarkkinoilla on ruuhkaa ja hinta laskee nopeasti päälajikkeiden sadon kypsyessä.

Mansikan satokauden pidentäminen - joko aikaistamalla tai viivyttämällä - voi parantaa alan kilpailukykyä. Sadon aikaistaminen on ollut tavoiteltua korkeamman hinnan vuoksi, joskin tämä etu on kilpailevan tuontimansikan kautta vähentynyt. Mansikan satotaimia ja kausihuoneita käyttäen on mahdollista yhdistää istutusvuoden syyssato ja seuraavan vuoden varhaistettu sato (Karhu \& Hietaranta 2007). Sadon ajoitukseen on käytettävissä lajikevalinnan lisäksi harsokatteet, viljely voidaan toteuttaa kasvihuoneissa ja muovitunneleissa, ja satokauden jatkaminen satotaimien istutuksia ajoittaen on myös mahdollista. Tunneliviljely on toistaiseksi vähäistä, vain joitakin hehtaareja yli 3000 ha:n mansikka-alasta. Jatkuvasatoisilla eli päiväneutraaleilla mansikkalajikkeilla satokausi voi jatkua jopa lokakuulle asti. Näillä lajikkeilla kukka-aiheita kehittyy koko kasvukauden ajan eikä kehitys määräydy päivänpituuden mukaan.

Jatkuvasatoisen mansikan tutkimushanke alkoi MMM:n hankerahoituksella vuonna 2007 MTT Puutarhatutkimuksen vetämänä (Karhu \& Hietaranta,2008). Hankkeen kasvinsuojeluosio toteutettiin pääosin MTT Kasvinsuojelun koekentällä Jokioisilla vuosina 2008 ja 2009. Kasvinsuojelututkimuksen osatavoitteita olivat: 1) selvittää mansikan kasvintuhoojien esiintymistä ja merkitystä koko kasvukauden ajan kukkivan, jatkuvasti satoa tuottavan mansikan viljelyssä, 2) vertailla jatkuvasatoisen mansikan kasvintuhoojien esiintymistä ja merkitystä avomaalla ja kasvutunnelissa, 3) tutkia lajikkeiden välisiä mahdollisia eroja kasvintuhoojien vioituksen kohteena sekä 4) tutkia ja soveltaa biologisen torjunnan menetelmiä tärkeimpien kasvintuhoojien torjuntaan. Kokoavana tavoitteena oli jatkuvasatoisen mansikan kasvinsuojeluohjeiston laatiminen tarkkailu- ja torjuntatoimenpiteineen. Tässä esitetään tuloksia lähinnä vuoden 2008 aineistoon perustuen.

\section{Aineisto ja menetelmät Koekenttä}

Koealueet istutettiin mustalla muovilla katettuihin mataliin penkkeihin 12.5.2008. Lajikkeet olivat edellisenä vuonna Piikkiössä tehtyjen lajikehavaintojen perusteella Malling Opal (Englanti), Rita (Norja) ja Rondo (Norja) ja taimet tuotettiin Piikkiössä. Kastelua ja lannoitusta varten alueelle asennettiin tihkuletkut. Riviväleihin ja alueen ympärille kylvettiin nataseos. Identtiset koealueet perustettiin avomaalle ja 6 m leveään tunneliin. Lajikkeet istutettiin 25 taimen ruutuina kuutena kerranteena riveittäin satunnaistettuna, ruutujen väleihin istutettiin valkomarjaista ahomansikkaa. Ensimmäisenä vuonna pölytys tapahtui luontaisesti, toisena vuonna alueille sijoitettiin kimalaispesät Molemmat alueet suojattiin rastasverkoilla sen jälkeen kun oli todettu rastaiden aiheuttama runsas vioitus. Avomaalla ja tunnelissa seurattiin lämpötilaa ja suhteellista kosteutta kasvuston tasalla olevilla loggereilla, tunnelissa lämpötila nousi ajoittain jopa 35 asteeseen vaikka tunnelin sivuja avattiin. Talvisuojaus tehtiin kaksinkertaisella harsolla kattaen. Myyrätuhot olivat talvella niin suuret että alueet istutettiin uudelleen kesäkuun alussa 2009. Toisen vuoden koetuloksia ei siis alueelta saatu, mutta kasvintuhoojien kannat säilyivät viereisellä lajikekoealueella.

\section{Havainnot ja näytteet}

Alueilla seurattiin lentäviä tuholaisia keltaisilla ja sinisillä liima-ansoilla, jotka vaihdettiin viikoittain. Lehtinäytteitä kerättiin joka toinen viikko punkkien ja ripsiäisten laskentaa varten ja vatinäytteitä otettiin karistamalla lehdiltä ja kukinnoista hyönteisiä lähinnä kärsäkkäiden ja muiden kovakuoriaisten sekä luteiden ja ripsiäisten havaitsemiseksi. Tuholaisten lisäksi hyödylliset petohyönteiset ja -punkit sekä loispistiäiset laskettiin näytteistä.

Sato kerättiin kolme kertaa viikossa, lajiteltiin ja punnittiin. Lajittelu tehtiin sekä marjakoon että tuholais- ja tautivioitusten mukaan. Myös muut vioitukset huomioitiin. Satokausi jatkui tunnelissa lokakuun alkuun, avomaalla pakkanen lopetti sadonkorjuun jo syyskuun alussa vuonna 2008, mutta vuonna 2009 satoa kerättiin syyskuun loppuun saakka avomaallakin. 


\section{Kasvinsuojelu}

Tutkimuksen tavoitteiden mukaisesti kasvinsuojeluaineiden käyttöä vältettiin. Harmaahomeen (Botrytis cinerea) ja mansikan härmän (Sphaerotheca aphanis) torjuntaruiskutuksista pidättäydyttiin, koska haluttiin nähdä lajikkeiden ominaisuudet tautivioitusten suhteen. Vihannespunkin (Tetranychus urticae), ripsiäisten ja kirvojen torjuntaan käytettiin ansaripetopunkkia (Phytoseiulus persimilis), ripsiäispetopunkkeja (Neoseiulus cucumeris ja Neoseiulus barkeri) ja kesärikkaluteita (Orius majusculus). Torjuntaeliöt toimitti Biotus Oy, Jokioinen. Muiden hyönteistuholaisten torjuntaan oli varauduttu käyttämään pyretriiniä (Bioruiskute S), jolla on vain yhden vuorokauden varoaika.

\section{Tulokset ja tulosten tarkastelu Vihannespunkki}

Vihannespunkkia esiintyi jonkin verran jo taimissa vuonna 2008. Ennakoivana torjuntatoimenpiteenä ja samalla ripsiäisten torjumiseksi molemmille alueille levitettiin kesäkuun lopulla vuonna $2008 \mathrm{~N}$. cucumeris petopunkkeja $50 \mathrm{kpl} / \mathrm{m}^{2}$. Vihannespunkkien määrä nousi kuitenkin tunnelissa nopeasti heinäkuun puoliväliin mennessä, jolloin tunnelissa aloitettiin ansaripetopunkkien levitys, $10 \mathrm{kpl} / \mathrm{m}^{2}$. Levitykset toistettiin neljä kertaa heinä-elokuussa ja elokuun loppuun mennessä vihannespunkkien määrä oli pudonnut lähes nollaan. Avomaalla ei ennakoivan torjunnan jälkeen tehty muita petopunkkilevityksiä ja vihannespunkkien määrä pysyi kohtuullisena, kunnes elokuun lopulla ensin Rita-lajikkeella ja syyskuun aikana myös muilla lajikkeilla vihannespunkkien määrä nousi yli 20 kpl/lehdykkä. Vuonna 2009 ennakoiva punkkien ja ripsiäisten torjunta tehtiin levittämällä 23.6. $N$. cucumeris ja $N$. barkeri sekoitusta $80+80 \mathrm{kpl} / \mathrm{m}^{2}$. Ansaripetopunkkeja levitettiin sekä avomaalle että tunneliin $15 \mathrm{kpl} / \mathrm{m}^{2}$ vain kerran 8.7. Vihannespunkkien määrä pysyi vähäisenä koko kasvukauden ajan tunnelissa, avomaalla punkkeja oli jonkin verran enemmän, mutta huomattavasti vähemmän kuin edellisenä vuonna.

Vihannespunkki on merkittävä mansikan tuholainen sekä avomaalla että kausihuoneissa. Ansaripetopunkki sopii vihannespunkin torjuntaan kausihuoneessa erinomaisesti. $N$. cucumeris ja $N$. barkeri ovat paremmin sopeutuneet avomaalla vallitseviin olosuhteisiin, mutta niille vihannespunkit ovat toissijaista saalista. Petopunkkien levitys on tehtävä kun vihannespunkin aikuisia tai nymfiasteita on keskimäärin korkeintaan muutama kpl/lehdykkä. Tällöin kasvustossa on jo havaittavissa ensimmäisiä vaaleita vioituspilkkuja. Mahdollista toista levitystä varten lehtien tarkkailua jatketaan.

\section{Ripsiäiset}

Ripsiäisiä esiintyi kasveilla kumpanakin vuonna jonkin verran koko kasvukauden ajan. Ripsiäisiä torjuttiin ripsiäispetopunkkien levityksin kesäkuussa (ks. edellä) tavoitteena vähentää kukkiin kohdistuvaa vioitusta. Lisäksi v. 2008 levitettiin kesäkuussa kesärikkaluteiden nymfiasteita 3-5 $\mathrm{kpl} / \mathrm{m}^{2}$. Lajikkeilla oli eroja: Ritalla ripsiäisiä ja ripsiäisvioituksia esiintyi enemmän kuin muilla lajikkeilla (kuva 1). Ripsiäislajisto on vielä määrittämättä ja vasta määritysten jälkeen voidaan arvioida ripsiäisten merkitystä. Kelta-ansoissa ripsiäisiä esiintyi enemmän tunnelissa, sen sijaan kasvustonäytteissä ripsiäisten määrä avomaalla oli suurempi.

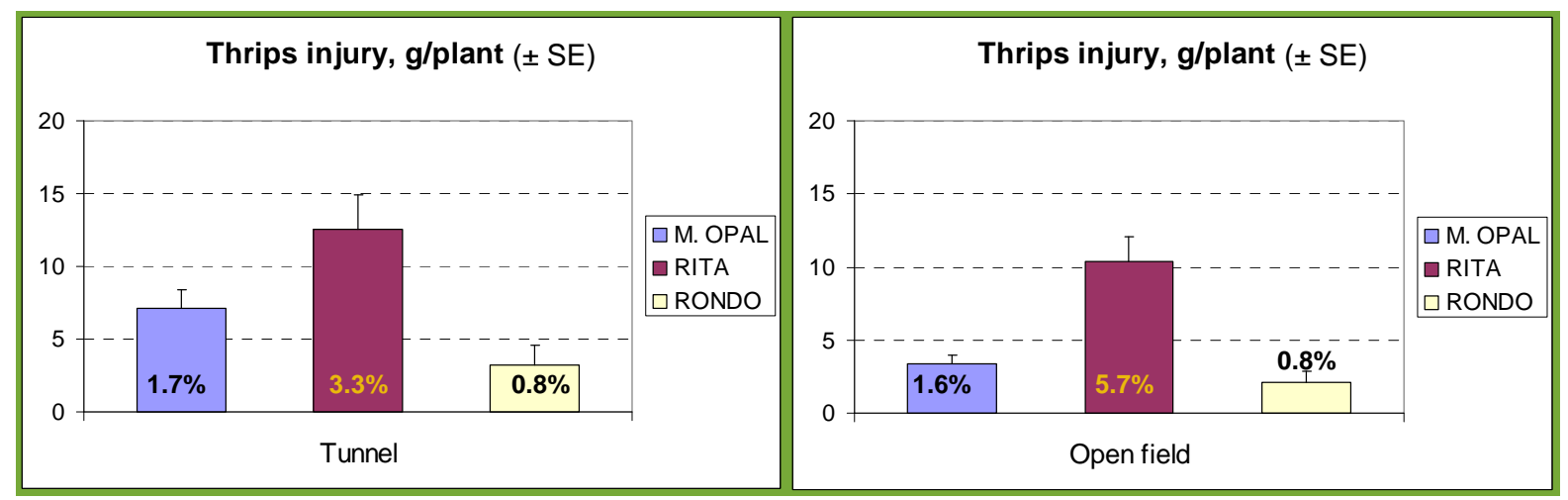

Kuva 1. Ripsiäisvioitukset tunnelissa ja avomaalla 2008. Prosenttiluku ilmaisee vioituksen osuuden koko sadosta. 


\section{Muut tuholaiset}

Merkittävistä mansikan tuholaisista vattukärsäkäs (Anthonomus rubi) esiintyi alueella kohtuullisen harmittomana ja vioitettujen nuppujenkin määrä vatinäytteissä jäi vähäiseksi. Peltoluteita (Lygus rugulipennis) esiintyi myös niukasti. Rapsikuoriaisia (Meligethes aeneus) esiintyi kukissa runsaasti loppukesällä, mutta sen aiheuttamat vioitukset jäivät vähäisiksi. Vuonna 2009 alueella esiintyi runsaasti valkovyölehtiäisen (Allantus cinctus) toukkia, jotka söivät lehtiä, mutta eivät aiheuttaneet suurempaa vioitusta kukille tai kypsyville marjoille. Lehtikirvoja esiintyi sekä avomaalla että tunnelissa, mutta niistä ei aiheutunut haittaa. Mainitut hyönteistuholaiset voidaan tarvittaessa torjua myös kukinnan aikana pyretriiniruiskutteilla, mikä aiheuttaa kuitenkin torjuntaeliöiden tuhoutumisen mahdollisesti petopunkkien muna-asteita lukuun ottamatta. Toinen vaihtoehto on tiaklopridi, jonka haitta ripsiäispetopunkeille on pienempi, mutta kesärikkaluteille suurempi kuin pyretriinillä (Koppert, 2009). Etanat, maakiitäjäiset, yökköstoukat ja kääriäistoukat vioittivat marjoja tunnelissa jonkin verran enemmän kuin avomaalla (kuva 2). Muista kasvintuhoojista räkättirastaat vioittivat marjoja ennen rastasverkon asennusta ja peltomyyrät tuhosivat talvehtivan kasvuston.

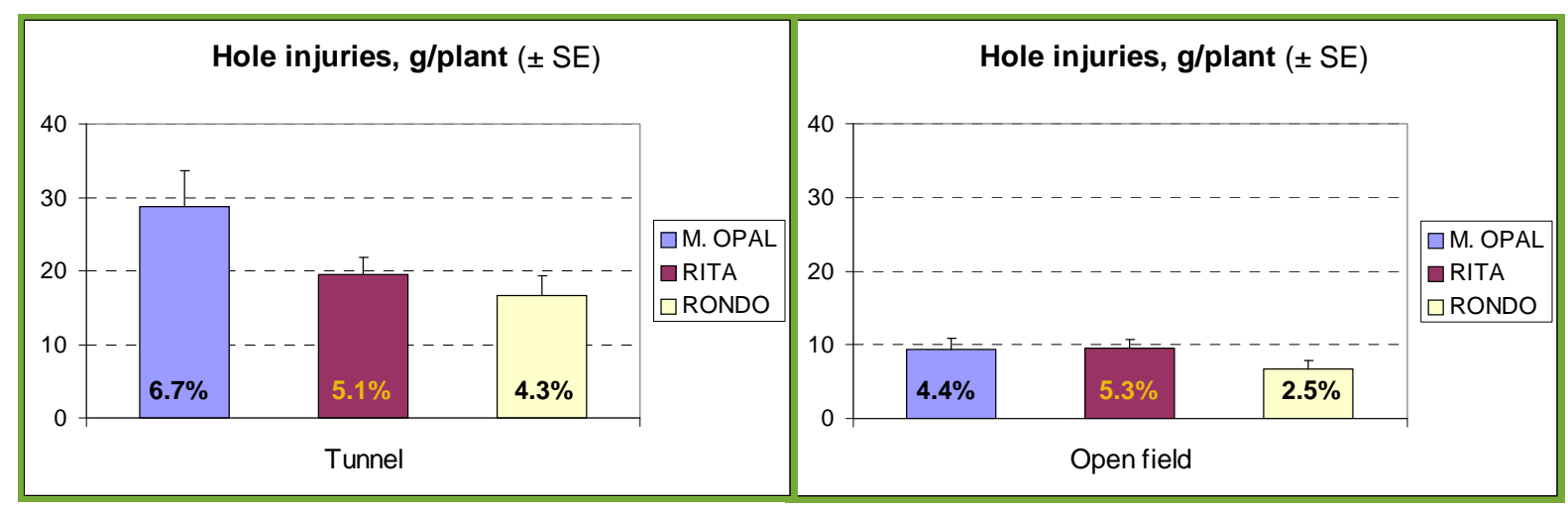

Kuva 2. Perhos- ja pistiäistoukkien, kovakuoriaisten ja etanoiden aiheuttamat kolovioitukset tunnelissa ja avomaalla vuonna 2008. Prosenttiluku ilmaisee vioituksen osuuden koko sadosta.

\section{Taudit}

Harmaahome aiheutti avomaalla moninkertaisesti vioitusta verrattuna tunneliin ja Malling Opallajikkeella enemmän kuin muilla (kuva 3). Mansikan härmää ei alueilla havaittu lainkaan johtuen taimien puhtaudesta. Tunneliviljelyssä härmän esiintyminen on kuitenkin huomioitava kasvinsuojelusuunnitelmaa laadittaessa. Mansikan tyvimätä (Phytophthora cactorum) aiheutti Malling Opal-lajikkeella jonkin verran taimien tuhoutumista. Alueella oli esiintynyt tyvimätää useita vuosia aikaisemmin.

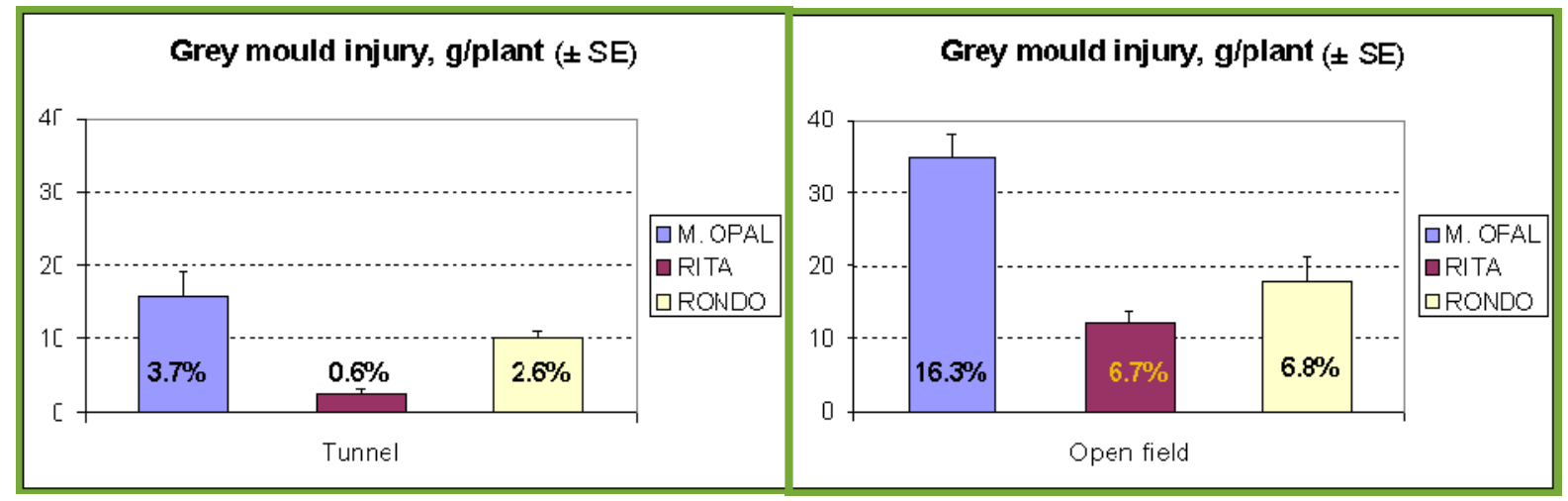

Kuva 3. Harmaahomeen aiheuttama satovioitus tunnelissa ja avomaalla vuonna 2008. Prosenttiluku ilmaisee vioituksen osuuden koko sadosta. 


\section{Satomäärä ja satoanalyysit}

Lajikkeiden järjestys myyntikokoisen satomäärän mukaan vuonna 2008 oli tunnelissa Malling Opal, Rondo ja Rita, avomaalla Rondo, Malling Opal ja Rita. Kausihuoneessa sato oli noin kaksinkertainen avomaahan verrattuna, mutta jos tarkastellaan satomäärää vain ensimmäisiin yöpakkasiin asti, erot pienenevät. Kauppakelpoinen sato - virheetön yli $18 \mathrm{~mm}$ - oli tunnelissa hiukan yli 70\% kokonaissadosta, sen sijaan avomaalla etenkin Malling Opal- ja Rita-lajikkeilla alle puolet (kuva 4). Marjapaino oli avomaalla suurempi, vastaavasti marjojen määrä vain noin puolet tunnelin marjamäärästä. Ritan marjat olivat kooltaan alle puolet Malling Opaliin verrattuna.

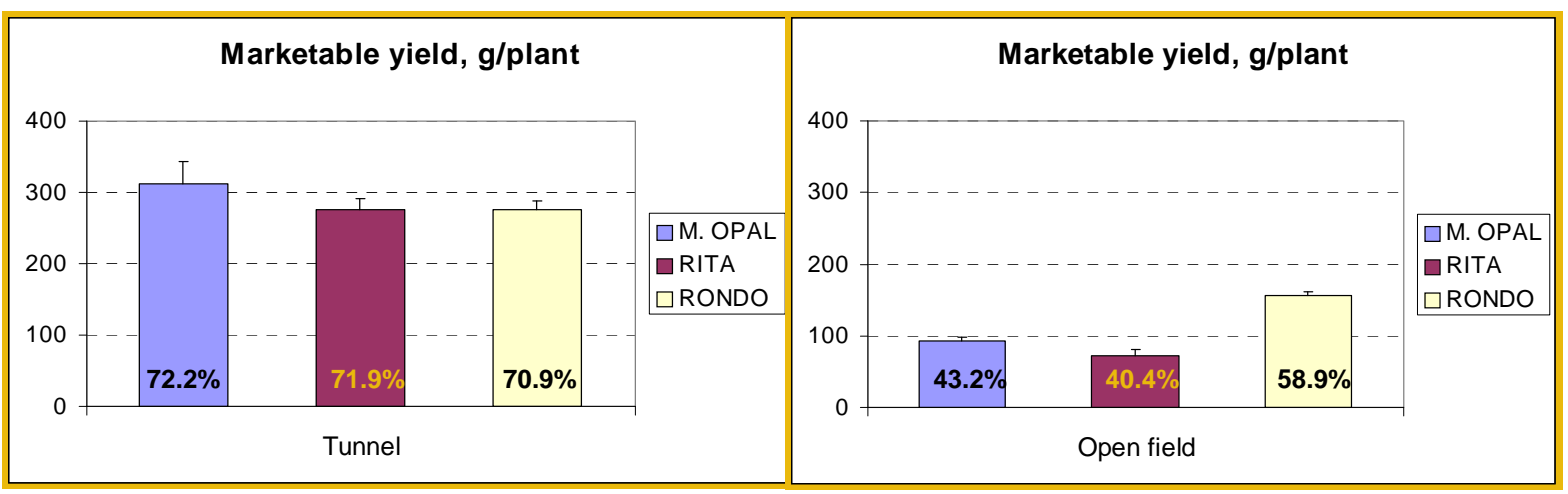

Kuva 4. Kauppakelpoinen sato tunnelissa ja avomaalla vuonna 2008. Prosenttiluku ilmaisee kauppakelpoisen sadon osuuden koko sadosta.

Sadosta määritettyjen vioitusten aiheuttajia oli lukuisia ja huomattava osa vioituksista oli muita kuin tautien tai tuholaisten aiheuttamia. Marjojen pehmenemisen ja sateen aiheuttamat marjojen pintaan syntyneet painumat muovia vasten muodostivat huomattavan osan vioituksista (kuva 5). Tunnelissa vioituksia edesauttoi ajoittain korkeaksi noussut lämpötila.

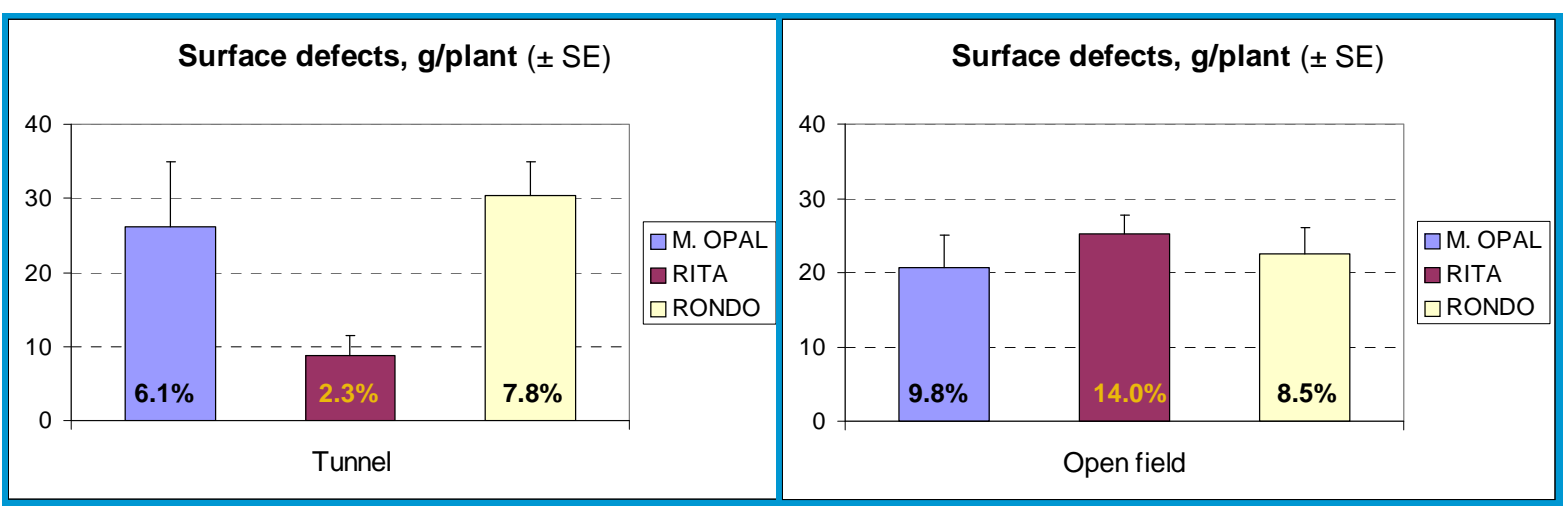

Kuva 5. Abioottisten pintavioitusten määrä tunnelissa ja avomaalla vuonna 2008. Prosenttiluku ilmaisee vioituksen osuuden koko sadosta.

Lievästi epämuotoisia marjoja esiintyi eniten Rondolla - syynä voi olla puutteellinen pölytys tai lievä hallavaurio ennemmin kuin hyönteisten aiheuttama epämuotoisuus (kuva 6). Myös marjojen halkeamista esiintyi jonkin verran kaikilla lajikkeilla. 'Nappipäisiä', selvästi luteiden vioittamia marjoja ei ollut juuri lainkaan.

Vioitusten luonne tunnelissa ja avomaalla oli erilainen: avomaalla oli kaikkia vioituksia suhteellisesti enemmän ja etenkin harmaahomeen vioitusta ja olosuhteiden aiheuttamia fysiologisia vioituksia esiintyi runsaammin kuin tunnelissa. Myös tuholaisvioitusten osuus oli avomaalla jonkin verran suurempi kuin kausihuoneessa. Malling Opal kärsi etenkin avomaalla eniten harmaahomeesta. Toukkien ja etanoiden aiheuttamia koloja esiintyi jonkin verran enemmän tunnelissa ja Malling Opalilla, rastaiden vioituksia muita vähemmän Rondolla avomaalla. 


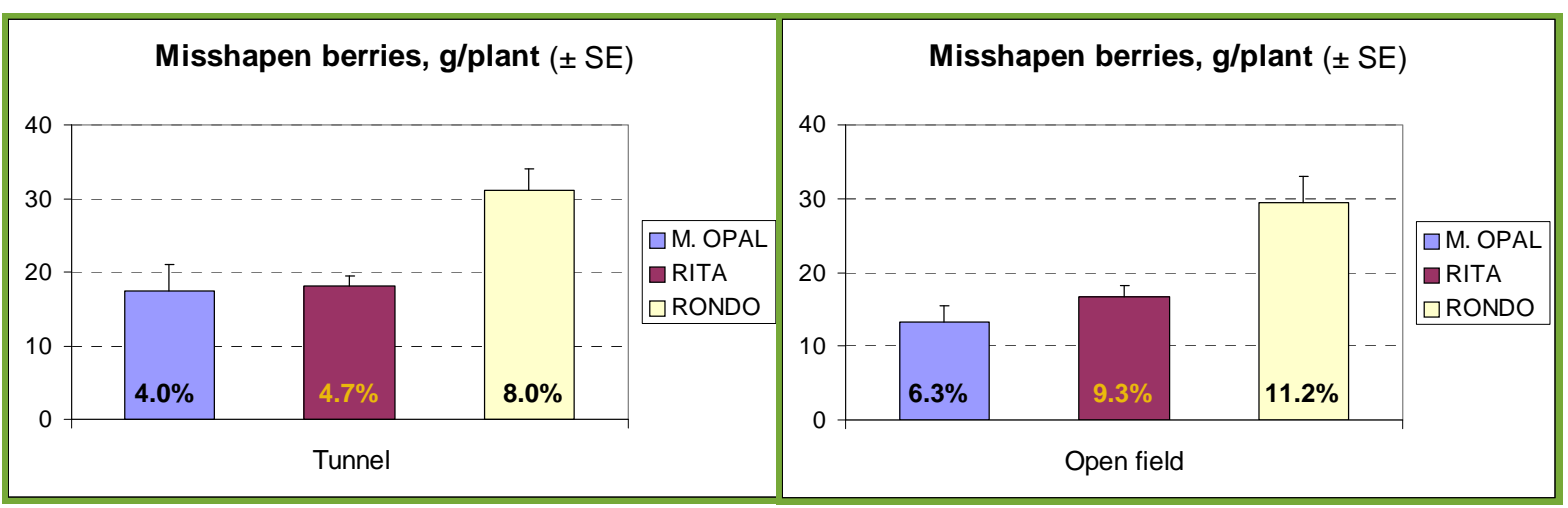

Kuva 6. Lievästi epämuotoisten marjojen määrä tunnelissa ja avomaalla 2008. Prosenttiluku ilmaisee vioituksen osuuden koko sadosta.

\section{Johtopäätökset}

Näiden tulosten perusteella on ennenaikaista arvioida jatkuvasatoisen tunneliviljelyn kasvinsuojelun kustannuksia ja viljelyn kannattavuutta. Jatkuvasatoisella mansikalla tunneliviljely on välttämätöntä etenkin harmaahomeen aiheuttaman riskin vähentämiseksi. Tutkimuksessamme mansikan härmästä ei ollut haittaa, mutta käytännössä härmän torjunta on olennainen osa tunneliviljelyä. Harmaahomeen ja mansikan härmän torjuntavalmisteiden haitalliset vaikutukset tuholaisten biologiseen torjuntaan ovat käytännössä vähäisiä.

Tuholaisten merkitys vaihtelee paljon alueellisista olosuhteista, ympäristön kasvillisuudesta ja viljelyhistoriasta johtuen. Koealueemme lähellä ei ollut vanhaa mansikkamaata, mutta sen sijaan vadelmaa, jolla on useita yhteisiä tuholaisia mansikan kanssa. Vihannespunkin torjunta onnistuu tunnelissa ansaripetopunkkien avulla hyvin, avomaalla sen sijaan ripsiäispetopunkkien käyttö voi olla tehokkaampaa. Petopunkkilevityksiä on tarvittaessa tehtävä useaan kertaan. Koealueella ei esiintynyt mansikkapunkkia (Phytonemus pallidus), mutta sen biologiseen torjuntaan on myös varauduttava. Ripsiäispetopunkit soveltuvat hyvin mansikkapunkin torjuntaan niin avomaalla kuin tunnelissakin (Tuovinen ym. 2009). Ripsiäisten torjunta petopunkkien tai petoluteiden avulla onnistunee paremmin tunnelissa kuin avomaalla. Kirvojen torjuntaan on käytettävissä petoluteita, harsokorennon toukkia ja parasitoideja, joita ei tässä tutkimuksessa kuitenkaan tarvittu. Muiden tuholaisten torjuntaan on toistaiseksi käytettävä hyväksyttyjä kasvinsuojeluaineita. Jatkuvasatoisessa mansikanviljelyssä tuholaisten torjunta-aineiden käyttö on pyrittävä rajaamaan ennen kukinnan alkua tehtäviin ruiskutuksiin.

\section{Kirjallisuus}

Hietaranta, T., Karhu, S. 2008. Jatkuvasatoista mansikkaa pitkälle syksyyn. Puutarha \& kauppa 12, 25-26: 14-15.

Karhu, S., Hietaranta, T. 2007. Mansikkalajikkeita ajoitettuun sadontuotantoon. In: Saila Karhu (toim.). Sadonkorjuu - Tutkittua puutarhatuotantoa 2003 - 2005. Harvest - Horticultural Research Results 2003 - 2005. MTT:n selvityksiä 139: 26-28. [ $\underline{\text { Url] }}$ Verkkojulkaisu päivitetty 9.5.2007.

Koppert. 2009. Side effects. http://side-effects.koppert.nl/

Tuovinen, T., Lindqvist, I., Kauppinen, S., Kivijärvi, P. 2009. Integration of biological mite control and conventional insect control in strawberry. Acta Horticulturae 842: 661-664. 